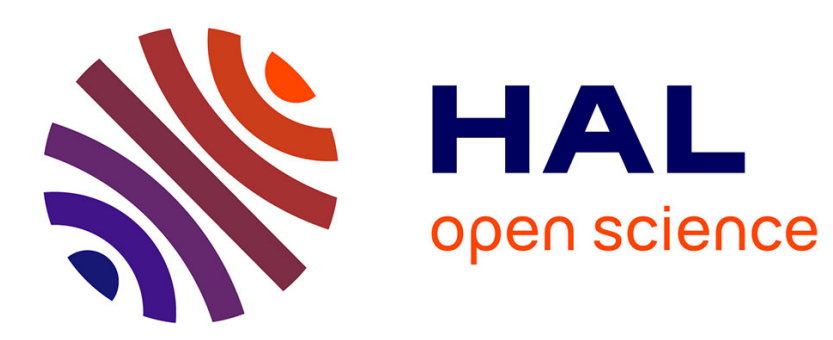

\title{
Review article: Knowledge of features in fossilized second language grammars \\ Laura Domínguez
}

\section{To cite this version:}

Laura Domínguez. Review article: Knowledge of features in fossilized second language grammars. Second Language Research, 2007, 23 (2), pp.243-260. 10.1177/0267658307076595 . hal-00570728

\section{HAL Id: hal-00570728 \\ https://hal.science/hal-00570728}

Submitted on 1 Mar 2011

HAL is a multi-disciplinary open access archive for the deposit and dissemination of scientific research documents, whether they are published or not. The documents may come from teaching and research institutions in France or abroad, or from public or private research centers.
L'archive ouverte pluridisciplinaire HAL, est destinée au dépôt et à la diffusion de documents scientifiques de niveau recherche, publiés ou non, émanant des établissements d'enseignement et de recherche français ou étrangers, des laboratoires publics ou privés. 


\section{Review article}

\section{Knowledge of features in fossilized second language grammars}

\section{Laura Domínguez University of Southampton}

Received October 2006; revised December 2006; accepted December 2006

This article examines two recent books on fossilization and assesses their contribution to our understanding of the causes of non-target performance in near-native grammars. The different accounts of fossilization these books present is outlined; one takes the view that a critical period prevents subjects from accessing syntactic features which are not available in their first language (L1), while the other takes the view that maturational problems make it difficult for learners to work out the mapping between syntactic features and their morphological expression. The contrasting consequences of each of these phenomena upon our understanding of fossilization, end-state grammars and the role played by the first language are highlighted. The possibility of moving away from a parameter-setting model of second language acquisition is discussed.

Franceschina, F. 2005: Fossilized second language grammars: the acquisition of grammatical gender. Amsterdam: John Benjamins. In the series Language acquisition and language disorders, edited by Harald Clahsen and Lydia White, Volume 38. xxiii + 288 pp. US\$138 hard. ISBN 902725298 X.

Lardiere, D. 2007: Ultimate attainment in second language acquisition: a case study. Hillsdale, NJ: Lawrence Erlbaum. vii + 273 pp. US\$59.95 hard. ISBN 0805834567.

\section{Divergent L2 end-state grammars}

One unresolved question in second language acquisition is why certain morphosyntactic properties of stable grammars diverge from native

Address for correspondence: Laura Domínguez, Modern Languages, University of Southampton, Avenue Campers, Level Three, Southampton, S017 IBJ, UK; email: L.Dominguez@soton.ac.uk 
forms despite continuous exposure to target input, a phenomenon known as 'fossilization' (Selinker, 1972). The fact that some learners do not seem to be able to achieve nativelike representations despite the availability of rich linguistic input is known as 'Orwell's Problem' (Chomsky, 1986) and contrasts with the observation that children manage to acquire target forms successfully in first language acquisition despite the poverty of stimulus. Similarly, the fact that fossilization is a widespread phenomenon but only observed in second language (L2) acquisition suggests that the processes assisting first language acquisition may not be available for learning a second language, an observation that has motivated much recent research on second language acquisition. Two contrasting positions are evident in the literature. On the one hand, the Failed Functional Features Hypothesis (FFFH) (Tsimpli and Roussou, 1991; Smith and Tsimpli, 1995; Hawkins and Chan, 1997) proposes that grammars fossilize because grammatical features, which constitute the basis of linguistic representations, are only accessible during first language acquisition. On the other hand, the Missing Surface Inflection Hypothesis (MSIH) (Haznedar and Schwartz, 1997; Lardiere and Schwartz, 1997; Prévost and White, 2000; Haznedar, 2001) proposes that deficits observed in stable grammars are not to be explained by the misrepresentation of formal features, but rather by problems with the mapping of those abstract features onto their corresponding surface forms. Under the latter view, and in contrast with FFFH, fossilization is not directly related to the availability to Universal Grammar (UG) but to a deficit in the interaction between the core syntax, which is unimpaired, with other grammatical modules subject to maturational constraints. The two books examined in this review article present evidence for these contrasting views: Franceschina's book supports FFFH, whereas Lardiere's book supports MSIH.

The different positions adopted by the authors have different consequences when divergence in L2 is expected. Specifically, for Franceschina, fossilization of certain areas of the grammar where the L1 and the target grammar differ in terms of features will be expected, whereas for Lardiere it is the combination of different factors like L1 transfer, type of morphology (bound vs. free morphemes) and complexity in the syntax-to-morphology mapping that will determine which areas of the grammar will fossilize. 
These two books present an extremely valuable contribution to the ongoing discussion of what constitutes knowledge of a (second) language, and how and when such knowledge cannot be attained. The fact that they represent and support different ends of the spectrum enables us to attack these issues from two opposing positions and therefore achieve a deeper insight into the problems involved. Furthermore, some of the different views defended in these books suggest a need to consider a move away from a long-standing model of second language acquisition (SLA) based on parametric differences to a more interface-based approach.

\section{Structure and focus of the books}

Franceschina's book, a revised version of her doctoral dissertation, tests whether a strong version of the FFFH can account for problems in the acquisition of gender by near-native second language learners of Spanish. The 68 subjects $^{1}$ who participated in her study were divided into two groups according to their first language: the -gen group, which included 15 speakers of English where the uninterpretable feature [ugender] is not observed, and the -gen group, which included 53 speakers of a number of languages (French, Arabic, Italian, Greek, German and Portuguese) where this feature is observed. By comparing the results of these two groups separately Franceschina aims to test the hypothesis that the absence of the gender feature is the determining factor that explains differences in target-like performance between the two groups.

The book is divided into six chapters. The first three chapters introduce key assumptions in supporting the author's claim that divergence in L2 end-state grammars can be accounted for by the absence of appropriate representational resources in the L2 (e.g. an uninterpretable gender feature) (p.6). These assumptions are summarized in the following three points:

- L2 grammatical representations are UG-constrained in the same way that $\mathrm{L} 1$ representations are.

- Parameterized functional features are subject to a critical period.

- The subset of features selected in first language acquisition is fully available for the construction of the L2 grammar's lexicon.

\footnotetext{
${ }^{1}$ Numbers of subjects tested vary from task to task.
} 
One of the important consequences of these assumptions is that transfer from the L1 will affect L2 acquisition. However, Franceschina supports a narrow view of transfer which is based on the assumption that only those features that are present in the learner's L1 (i.e. $[\mathrm{F}]_{\mathrm{L} 1}$ ) can be transferred and used in the construction of representations in the second language (i.e. $\operatorname{LEX}_{\mathrm{L} 2}$ ) (p.38). In contrast, computational resources, which for her are universal and invariant across languages, are not subject to transfer because they are necessarily present in all grammars. She also argues that even if features from $[\mathrm{F}]_{\mathrm{L} 1}$ are transferred to construct L2 representations, both grammars might not end up being identical for at least the following three reasons (p.38):

- Some of the resources in $[\mathrm{F}]_{\mathrm{L} 1}$ may be superfluous to the construction of the L2 grammar and consequently will not be used in the construction of $\mathrm{LEX}_{\mathrm{L} 2}$.

- Lexical items from the L1 may be assembled in a different way in the L2 if required by the $\mathrm{L} 2$ input.

- Those elements for which there is no universal/parameterized distinction may be different in the two grammars.

What is interesting about Franceschina's model is that it does allow the possibility that learners may resort to features $[\mathrm{F}]_{\mathrm{L} 1}$ to create new representations for properties in the L2 even though they are not based on exactly the same feature. It is important to note that although this compensatory strategy may seem to provide native-like representations of the L2, in these cases learners will in fact be 'operating on the basis of nonnative representations' (p.41). For instance, the author argues that even in those cases when Chinese speakers use wh-movement correctly in English, they might be assigning non-nativelike interpretations to those sentences since such construction does not exist in their native language.

Chapter 3 is a review of existing theories on ultimate attainment in SLA including biological, social, cognitive and linguistic accounts and, although perhaps more than necessary for the purpose of the book, it helps to frame the author's views on acquisition. In Chapter 4 an analysis of grammatical gender is introduced. Following Carstens (2000), Franceschina assumes that "nouns are inherently marked for gender, in the sense that they enter the numeration with valued interpretable features" (p.84). In her analysis the feature gender does not head its 
own functional projection, does not motivate movement itself and is a 'free-rider' which values the gender features of adjectives and D items it encounters in its way to $n$ and Num (p.85). In this respect, the syntactic gender feature in nouns is qualitatively different than the gender feature found in other categories, such as adjectives. This chapter also presents a review of relevant literature on the acquisition of gender. The interesting point that arises from comparing acquisition of gender in L1 and L2 is that children seem to learn grammatical gender quite early and in an error-free fashion whereas adults have persistent problems in this area. Also relevant is the observation that having overt gender marking in the L1 seems to assist in acquiring gender in the L2 (Bruhn de Garavito and White, 2000; White et al., 2001), an observation compatible with Franceschina's hypothesis that the + gen group will outperform the -gen group. Chapter 5 introduces the experimental design which consists of an oral interview ${ }^{2}$ and a series of experimental tests which follow the elicitation techniques proposed in Hawkins (2001) "with the aim of tapping the same area of the grammar through different performance measures" (p.130). The oral and written elicitation tasks include a guessing game, a missing word task, a multiple choice task, a grammaticality judgement task, a novel word task and a gender assignment task. Statistical analyses of the results of all tasks indicate that there is indeed a higher accuracy level in the + gen group. When subjects' performance in all the tasks was compared, the + gen group was systematically indistinguishable from the native group whereas the gen L2 speakers did not perform badly but were consistently less targetlike than the + gen L1 group (p.187). For instance, in the guessing game task, designed to test subjects' use of gender agreement cues of pronouns and adjectives to interpret the meaning of sentences, the + gen group achieved an overall accuracy rate of $92.4 \%$, which was very close to the $97.93 \%$ accuracy rate achieved by NSS, whereas the -gen group only reached $81.33 \%$ accuracy. The following table shows a comparison of the subjects' performance across five different tasks (adapted from Franceschina (2005: 188): ${ }^{3}$

\footnotetext{
${ }^{2}$ Only subjects who were native speakers of Portuguese or Italian participated in the spontaneous speech production task.

${ }^{3}$ Results for the interviews and the novel word task (which are oral tasks) are excluded from the table.
} 
Table 1 Overall accuracy rates ( $n$-percentages) of the three groups in five tasks

\begin{tabular}{llllll}
\hline & $\begin{array}{l}\text { Guessing } \\
\text { game }\end{array}$ & $\begin{array}{l}\text { Missing word } \\
\text { choice task }\end{array}$ & $\begin{array}{l}\text { Cloze/multiple } \\
\text { correction }\end{array}$ & $\begin{array}{l}\text { Grammaticality } \\
\text { judgement task }\end{array}$ & $\begin{array}{l}\text { Assignment } \\
\text { check }\end{array}$ \\
\hline $\begin{array}{l}\text { Native } \\
\text { speakers }\end{array}$ & 97.93 & 98.89 & 98.04 & 95.41 & 99.62 \\
$+\begin{array}{l}\text { gen } \\
\text { group }\end{array}$ & 92.4 & 96.93 & 98.33 & 95.27 & 99.29 \\
$-\begin{array}{l}\text { gen } \\
\text { group }\end{array}$ & 81.33 & 93.92 & 89.92 & 86.00 & 99.01 \\
\hline
\end{tabular}

The experiments were set up to rule out other possible variables such as type of gender marking, the form of gender cues, position of pronouns, word class present in context, structural context and use of semantic strategies. Franceschina concludes that the results constitute evidence to support her hypothesis that nativelike attainment is determined by the learner's L1 (p.190). The results also suggest that the type of gender marking (whether it is canonical or not) can affect the learners' performance indicating that the problematic items are those where gender is difficult to identify from morphological marking; however, Franceschina argues that this cannot be the full account of the problem since this factor seems to affect the -gen group to a much higher degree (p.187).

Lardiere adopts a different approach to investigate fossilization. Her book presents a longitudinal study of Patty, a native speaker of Hokkien and Chinese who moved to the USA in 1976 at the age of 22. What makes Patty an interesting case study is that some areas of her grammar have not improved over the past decades despite her aptitude for language learning, her amount of exposure to the target input, and the high number of opportunities for her to use English in her everyday routine. A comprehensive picture of Patty's knowledge of English is given in the form of naturalistic data collected in the course of three oral interviews, ${ }^{4}$ plus written data in the form of emails collected from 1997 2002, and the results from two grammaticality judgement tests. By combining longitudinal oral and written data with more focused tasks Lardiere aims to provide a view of the grammar of a learner at the steady state from various perspectives. What makes this study particularly

\footnotetext{
${ }^{4}$ The first recording took place after Patty had been living in the USA for 9 years; the second recording took place almost 9 years later and the final recording 2 months after the second one. Some of these data have been previously discussed in Lardiere (1998a; 1998b; 2000).
} 
interesting is that several relevant aspects of a stable grammar are analysed as a whole, including knowledge of finiteness, wh-movement, clausal word order and nominal phrases. This is quite a remarkable attempt at a comprehensive study compared to the relatively narrow question addressed by Franceschina. However, it soon becomes obvious that the task of getting all the pieces to fit reveals how complex the puzzle really is. This forces Lardiere to propose that more than one mechanism is required to explain the data.

The book is divided into 7 chapters. Chapters 1 and 2 introduce Patty's background and describe preliminary issues on ultimate attainment. Chapter 3 analyses the data focusing on those features that mark finiteness both in English and Chinese whereas Chapter 4 focuses on Patty's knowledge and use of overt morphology in English, including present and past tense. The acquisition of morphosyntactic phenomena, which are radically different in English and Chinese, are analysed as well, including $w h$-movement, subjacency, relative clauses and passives in Chapter 5; and knowledge of definiteness, gender and number in nominal phrases in Chapter 6. Chapter 7 discusses the conclusion that the disassociation between syntax and morphology can be problematic for the acquisition of certain syntactic phenomena, such as finiteness.

\section{Franceschina: knowledge of features}

What constitutes knowledge of a language? For Franceschina it is syntactic features which "stand for mental resources that play a fundamental role in the representation of linguistic knowledge" (p.10). Accordingly, in this book she focuses on the acquisition of uninterpretable parameterized features (e.g. gender in Spanish), which she claims are the features that seem to be problematic for L2 learners (p.11). Importantly, the view of parameterization that Franceschina follows differs from a more traditional view of parameter setting. Building on Chomsky (1998), she argues that "parameter setting is assumed to be restricted to optional feature selection from F" (p.10), which in turn assumes that features are either present in all languages (i.e. universal features), or they are optionally selected in some languages (i.e. parameterized features). This is a departure from a traditional view of parameterization in which children, who are innately endowed with all the 
principles and parameters given by UG, set the values of those parameters to either + or - during the course of acquisition on the basis of the input. For Franceschina, however, the value of parameters is [ \pm obligatory], which means that parameters that, from a traditional view, will be set with a negative value, will not be part of the L1 (for a similar argument, see Hawkins, 2001).

Franceschina aims to show that observed persistent divergence from the target language in second language acquisition results from a breakdown in the representational system and not problems with the peripheries. The following observations support this claim: first, if 'derailment' involves the peripheries, it would be expected that L2 will diverge in ways which are not "demarcated along syntactic lines' (p.58)'. The observations that Franceschina reports, however, appear to relate to syntactic distinctions. Second, omission of inflectional morphology should be phonologically conditioned, but in fact it appears to affect irregular morphemes where there are no phonologically problematic sequences of segments for L2 speakers, as well as regular morphemes where there are. In this respect, the author reviews a number of studies that have shown that problems with tense marking cannot be appropriately accounted for as phonological deficits. For instance, Liszka (2001) shows that Chinese learners do not have the same problems pronouncing the final consonant clusters in past participles that they show with the same forms in the past tense. Furthermore, Ionin and Wexler (2002) show that omissions of third person singular '-s' cannot be accounted for by phonological errors as omissions were observed at a similar rate in irregular verbs.

From Franceschina's views on parameterization it follows that although interlanguage grammars are constrained by Universal Grammar, only those features already present in the learners' L1 will be available for the construction of the L2. More importantly, where a property of an L2 is determined by a feature not selected in the L1, an L2 learner will not be able to represent this property in the same way as native speakers. The results in Franceschina's tests show that indeed there are significant quantitative differences between the -gen group and the +gen group. At this point it is important to note that Franceschina does not argue that the -gen group has not learnt gender in Spanish as this group performs quite high in all tests. The important 
observation is that this group performed significantly less well than the + gen group. This view of 'failure' contrasts with the view of other researchers who argue that target-like competence does not mean being indistinguishable from natives in performance. In fact, despite the predictions formulated by the FFFH, the results in Franceschina's tests show that all the subjects had knowledge of gender in Spanish. This result leads the author to conclude that grammatical gender alone cannot be taken as conclusive evidence in favour of the FFFH, which predicts that parameterized functional features cannot be acquired after childhood unless they are present in the L1 (p.192). She suggests that it is possible that the high accuracy shown by the -gen group could be explained because learners may make use of additional compensatory strategies, such as training and verbal ability, to help them produce structures which resemble the target forms. This explanation reconciles the original ideas behind the FFFH regarding the existence of a critical period for the acquisition of features with the observation that, although still problematic, knowledge of features not present in the L1 can reach levels of accuracy that can hardly be regarded as a failure. However, for Franceschina the representations achieved via these compensatory strategies are qualitatively different from those provided from UG. A similar argument is discussed in Hawkins and Hattori (2006) where the authors argue that, despite the existence of a critical period for accessing features, which are necessary for constructing L2 grammars, learners can still construct new representations using alternative resources available from UG. This means that although divergence from the target form is expected in areas where a feature mismatch exists, learners may still be able to find a way to learn those features. In these cases, however, linguistic performance will over-represent what learners know about the features in the target grammar.

Franceschina also argues that even if the target feature exists in the learner's first language, successful acquisition of that feature may not always be possible. She states that having a given feature in the learner's native grammar "is a necessary condition for achieving a fully targetlike grammar, but it is not a sufficient one' (p.198).' This is because for her the amount of exposure to input necessary to adapt features into the L2, as well as learner's own linguistic development, play a role in the pattern of variation in L2 outcomes. This is a caveat to her proposal 
which does not follow from the results of her study since the + gen group behaved indistinguishably from native speakers showing that they had achieved a fully targetlike grammar with respect to gender.

\section{Lardiere: the role of the peripheries}

Lardiere adopts a different view to address fossilization as she is focused on "determining the nature of the relationship between knowledge of abstract grammatical features and production of the morphological and syntactic forms typically assumed to constitute evidence of those features' (p.19). The abstract grammatical feature that is central in Lardiere's analysis is finiteness, which is introduced and discussed extensively in Chapter 3.

Despite the fact that finiteness is usually evidenced cross-linguistically by verbal inflection, the premise in Lardiere's work is that finiteness and verbal inflection must be analysed separately. ${ }^{5}$ There are at least two arguments in this book to support this: first, English does not show a morphological correlate for every expression of finiteness, which makes it an unreliable cue for second language learners; second, it can be argued that even languages with no verbal morphology, like Chinese, have finiteness (Li, 1990). Also crucial to Lardiere's analysis is the fact that there are other observable correlates of finiteness. For example, verb raising has long been linked to the feature strength of Tense and Agreement within IP (Pollock, 1989). Case marking is another example because a $[+$ finite feature, associated with a functional category Tense, triggers subjects to check their nominative case feature in Spec,TP (Chomsky, 1995). Following this line of thought, Lardiere hypothesizes that even if verbal morphology is omitted in Patty's speech we can still test whether she has acquired finiteness by looking at whether her knowledge of verb raising and case marking is targetlike. This prediction has been attested in child acquisition since children exposed to [ + finite] languages show knowledge of these properties even at the root infinitive stage. For instance, when German children use finite forms the verb is consistently in second position, and when they use non-finite forms the verb appears in final position (Poeppel and 
Wexler, 1993; Wexler, 1994), which shows that they have learnt the [+/- finite] distinction. Lardiere also discusses recent work on the acquisition of K'iche' Maya by Pye (2001), which supports the idea that verb raising may be a more reliable cue for children to learn the $+/-$ finiteness distinction in this language. The analysis of Patty's data is relevant to this discussion because Patty frequently omits inflectional verbal morphology, and her rates of omission do not decrease from the first to the last recording which indicates that this is an area in Patty's grammar that has fossilized. For instance, she only uses third person singular '-s' $4-5 \%$ of the time, after more than 25 years of exposure to English, and her use of past tense marking is less than $35 \%$ in obligatory past contexts. ${ }^{6}$ One possibility is that Patty does not have syntactic representations for $\mathrm{T}$ because she lacks the corresponding functional category (Vainikka and Young Scholten, 1994; 1996). However, Lardiere presents the following evidence to show that Patty has a full TP and that her knowledge of finiteness is indeed nativelike:

- Her use of null subjects is very low (2\%) indicating that she knows that subjects must overtly move to Spec,TP in English. She also shows nativelike use of nominative case marked subjects in finite clauses.

- Pronominal case marking is correctly distributed, which indicates that she has a TP node above VP.

- Non-lexical categories are more likely to be marked with finiteness (78\%) showing different behaviour depending on the category of items that affixes are attached to.

- Past and present agreement markings for auxiliary and copular forms are quite high. Her use of copular/auxiliary be is argued to be nativelike. In fact, Lardiere argued for the possibility that Patty's overgeneralization of this verb may be a compensation strategy for her lack of verbal affixation to represent finiteness.

\footnotetext{
${ }^{6}$ Lakshmanan and Selinker (2003) argue that Patty's low suppliance of past tense forms may signal grounding and/or lexico-semantic distinctions; consequently, although Patty's knowledge of past tense marking may be divergent from the target language, it may still be congruent with her own interlanguage. This implies that Patty's real use of past tense may be underrepresented in Lardiere's analysis. However, Lardiere shows that Patty uses past tense with roughly the same consistency for both foregrounding and backgrounding in her spontaneous narrations (p.117), which rules out Lakshmanan and Selinker's hypothesis. For a detailed response to Lakshmanan and Selinker, see Lardiere, 2003.
} 
- Irregular verbs are consistently past-marked, evidencing that Patty only has problems with past tense when it is an affix.

- In a grammaticality judgement task Patty correctly rejects sentences with verb-raising over adverbs that are ungrammatical both in Chinese and in English. According to Eubank (1994) if Patty did not know finiteness she would allow optional verb raising in her grammar.

- Patty knows 'do support', a characteristic linked to finiteness in English.

Lardiere's interpretation of these observations is that omission of finite morphology does not necessarily imply lack of finiteness. These results are similar to those observed in child first and second language acquisition where sentences with bare verbs are consistently marked with nominative Case and the children's use of copular be is targetlike (Haznedar, 2001; Ionin and Wexler, 2002; Paradis et al., 2004). It is important to note that in these studies whether verbs were inflected in the children's L1 did not seem to play a role.

Lardiere's account of Patty's low production of tense marking is based on an interface approach to finiteness; in particular, the author claims that it is the mapping of syntactic knowledge onto the corresponding surface morphological form which is problematic for second language learners. For Lardiere the correspondence rules by which semantic or syntactic categories are morpho-phonologically expressed are fragile and therefore prone to be problematic, whereas processes of core syntax that are not affected by maturational processes will be intact (p.9). In this respect, since Patty shows knowledge of verb raising and case marking in English, Lardiere concludes that Patty has knowledge of the finite/non-finite distinction but has not mastered the morphological correlates of finiteness (p.94).

Lardiere offers other possible explanations for why Patty may find past tense marking problematic beside the mapping deficit. One is the fact that there is a many-to-one function-form pairing in past tense marking in English (p.127), which makes the use of this form quite complex; another is based on L1 transfer. More precisely, Lardiere proposes that omission of past tense morphology can be due to a phonological bias since neither Hokkien nor Chinese allows final consonant clusters. This suggestion is supported by two findings: the fact that 
irregular verbs, which do not end in a consonant cluster, are consistently past-marked, and the fact that Patty's omission rate is much lower in the written data. A revealing result is that Patty produces nearly all instances of past participles with a final consonant cluster without affixal inflection as predicted (p.108). This contrasts with previous research which has shown that past participles were unaffected by phonological deficits in the speech of Chinese learners of English who at the same time had problems producing past tense morphology (Liszka, 2001). It is evident that the phonological deficit can only account for certain types of omission errors, specifically those where particular consonant clusters occur. Others, like the low use of third person singular morphology or Patty's low marking of plural on quantified and unquantified expressions require a different explanation.

For Franceschina, acquisition problems are highly dependent on the learner's L1. In contrast, there is an implication in Lardiere's analysis that both success and failure in acquisition are not determined by the learners' L1. For instance, Patty's targetlike performance on articles does not seem to be a consequence of a facilitative effect from the L1 as suggested in White (2003). Her supply rate of articles is very high ( $84 \%$ for definite articles and $75.5 \%$ for indefinite), despite the fact that there are no articles in Chinese. Lardiere also argues for the presence of a strong feature in C in Patty's grammar since acquisition of I-to-C movement of modal verbs, auxiliaries, the copula and expletive $d o$ is attested by the data. What is still surprising is that Patty has problems with present tense morphology but shows nativelike knowledge of other complex areas like wh-movement and subjacency, which are not present in her L1. Another possible complication for Lardiere's proposal is that it cannot fully account for why certain learners do not find the syntax-to-morphology mapping problematic. For instance, a Chinese speaker in Hawkins and Liszka's (2003) study behaved very differently from Patty as this subject's rate of use of past tense morphology was as high as $77 \%$ which clearly contrasts with Patty's $35 \%$ production. Of course, this also highlights the shortcomings of not having a population of subjects so that results from a number of learners can be compared.

Finally, Lardiere also argues that the parametric approach to SLA should be revised because some of the features attributed to a particular parameter may be available in languages for which it is not active 
(e.g. the strong $[\mathrm{wh}]$ feature that triggers movement of $w h$-elements in relative clauses in English, which is weak or absent in Chinese). More importantly, Lardiere observes that the selection of the setting of a particular parameter does not result in the elimination of the other possible value of that parameter, as is suggested by Patty's use of L1 based and L2 based strategies to form the passive (p.179). For Lardiere this is at the very least problematic for a view of parameter setting which regards parameter values as being mutually exclusive. Although Lardiere's proposals on parameterization may be congruent with her own analysis of Patty's data, the suggestion that parameter-based models of SLA need to be abandoned remains controversial, especially in the light of the results found by Franceschina.

In the final discussion Lardiere proposes that parametric views of acquisition need to be replaced by models that can adequately represent the role of the peripheries. Although this is an interesting proposal that is becoming increasingly accepted, it is necessary for future research studies of this kind to explicitly describe the mapping rules that learners need to figure out, as well as describe how knowledge of core syntax is successfully obtained.

\section{Conclusions}

These two books are the latest attempts at providing a model of acquisition that accurately accounts for persistent L2 divergence. They seek a better understanding of the role that age, the learners' first language, and the interfaces play in the acquisition of a second language. Although bringing our knowledge of these crucial aspects closer to a well-rounded understanding of fossilization, the analysis in these books also reveals two opposing accounts of non-nativelike feature-related phenomena; specifically, that final attainment is unsuccessful because UG does not provide the necessary resources to construct new representations in the L2 (Franceschina) and, in contrast, that it is the application of those resources that is problematic (Lardiere). Whilst the first enjoys the benefit of being a good indicator of L2 divergence, the latter suggests an explanation for observed targetlike performance in grammatical areas where Franceschina would have predicted divergence. 
Moreover, these books attest that defining, measuring and predicting what learners know about the systems they are acquiring is not an easy task. For instance, the varying types of experimental design presented in these two studies have different effects on the scope of each of the proposed analyses. In this respect, the hypothesis-driven experiments set up by Franceschina accurately measure subjects' knowledge of the feature gender, but may not be enough evidence to characterize fossilization as a whole. Conversely, the richness in Lardiere's observation-driven data allows her to analyse a wide range of relevant phenomena, providing us with a more inclusive picture of an end-state grammar, but it resists being accounted for with a single explanation.

Finally, these results illustrate the complexity behind learners' grammars. Lardiere's analysis shows that Patty's performance underrepresents what Patty knows about the target grammar since her nontargetlike performance in fact consists of underlying targetlike representations. On the other hand, as Franceschina suggests, it is also possible that a learner's output over-represents linguistic knowledge and that target-like representations may not underlie the same structures as in the target grammar (see also Wagner, 1999; Myles, 2004). The task for future research is to assess how the predictions and observations of each of these two diametrically opposed positions can be accommodated in our current model of SLA.

\section{Acknowledgements}

Many thanks to Florence Myles, the reviewers and, in particular, to Margaret Thomas for comments and guidance.

\section{References}

Bobaljik, J.D. 2002: Realizing Germanic inflection: why morphology does not drive syntax. Journal of comparative Germanic linguistics 6, 129-67.

Bruhn de Garavito, J. and White, L. 2000: L2 acquisition of Spanish DPs: the status of grammatical features. In Howell, C., Fish, S. and KeithLucas, T., editors, Proceedings of the 24th Annual Boston University Conference on Language Development. Somerville, MA: Cascadilla Press.164-75. 
Carstens, V. 2000: Concord in minimalist theory. Linguistic Inquiry 31, 319-55.

Chomsky, N. 1986: Knowledge of language its nature, origin and use. New York: Praeger.

— 1995: The minimalist program. Cambridge, MA: MIT Press. 1998: Minimalist inquiries: the framework. MIT Occasional Papers in Linguistics 15, MIT Working Papers in Linguistics.

Eubank, L. 1994: Optionality and the initial state in L2 development. In Hoekstra, T. and Schwartz, B.D. editors, Language acquisition studies in generative grammar. Amsterdam: John Benjamins, 369-88.

Hawkins, R. 2001: Second language syntax: a generative perspective. Oxford: Blackwell.

Hawkins, R. and Chan, C. 1997: The partial availability of UG in second language acquisition: the 'failed functional features hypothesis'. Second Language Research 13, 187-226.

Hawkins, R. and Hattori, H. 2006: Interpretation of English multiple whquestions by Japanese speakers: a missing uninterpretable feature account. Second Language Research 22, 269-301.

Hawkins, R. and Liszka, S. 2003: Locating the source of defective past tense marking in advanced L2 English speakers. In van Hout, R., Hulk, A., Kuiken, F. and Towell, R., editors, The interface between syntax and lexicon in second language acquisition. Amsterdam: John Benjamins.

Haznedar, B. 2001: The acquisition of the IP system in child L2 English. Studies in Second Language Acquisition 23, 1-39.

Haznedar, B. and Schwartz, B. 1997: Are there optional infinitives in child L2 acquisition? In Hughes, E., Hughes, M. and Greenhill, A., editors, Proceedings of the 21st Annual Boston University Conference on Language Development. Somerville, MA: Cascadilla Press, 257-68.

Ionin, T. and Wexler, K. 2002: Why is 'is' easier than '-s': acquisition of tense/agreement morphology by child second language learners of English. Second Language Research 18, 95-136.

Lakshmanan, U. and Selinker, L. 2001. Analyzing interlanguage: how do we know what learners know? Second Language Research 17, 393-420.

Lardiere, D. 1998a: Case and tense in the 'fossilized' steady state. Second Language Research 14, 1-26.

_ 1998b: Dissociating syntax from morphology in a divergent L2 end-state grammar. Second Language Research 14, 359-75.

- 2000: Mapping features to form in second language acquisition, in Archibald, J. editor Second Language Acquisition and Linguistic Theory, Blackwell, Oxford, 102-29.

- 2003: Revisiting the comparative fallacy: A reply to Lakshmanan and Selinker, 2001. Second Language Research 19, 129-43.

Lardiere, D. and Schwartz, B. 1997: Feature-marking in L2 development of deverbal compounds. Journal of Linguistics 33, 327-53. 
Li, Y.-H.A. 1990: Order and constituency in Mandarin Chinese. Dordrecht: Kluwer.

Liszka, S. 2001: Explaining divergent tense marking in advanced L2 speakers. Essex Graduate Student Papers in Language and Linguistics 3, 59-69. Department of Language and Linguistics, University of Essex, UK.

Myles, F. 2004: From data to theory: the over-representation of linguistic knowledge in SLA. Transactions of the Philological Society 102, 139-68.

Paradis, J., Rice, M., Crago, M. and Richman, A. 2004: Missing Inflection or (Extended) Optional Infinitives? Comparing Child L2 English with English SLI. Paper presented at the 29 Annual Boston University Conference on Language Development, Boston University, Boston, MA.

Poeppel, D. and Wexler, K. 1993: The full competence hypothesis of clause structure in early German. Language 69, 1-33.

Pollock, J.-Y. 1989: Verb movement, universal grammar and the structure of IP. Linguistic Inquiry 20, 365-424.

Prévost, P. and White, L. 2000: Missing surface inflection or impairment in second language acquisition? Evidence from tense and agreement. Second Language Research 16, 103-33.

Pye, C. 2001: The Acquisition of Finiteness in K'iche' Maya. In. Do, A. H.-J. Domínguez, L. and Johansen, A., editors, Proceedings of the 25th annual Boston University Conference on Language Development. Somerville. MA: Cascadilla Press, 645-56.

Selinker, L. 1972: Interlanguage. IRAL 10, 209-31.

Smith, N. and Tsimpli, I.M. 1995: The Mind of a Savant: Language Learning and Modularity. Oxford: Blackwell.

Tsimpli, I.M. and Roussou, A. 1991: Parameter-resetting in L2? In UCL Working Papers in Linguistics 3, 149-69

Vainikka, A. and Young-Scholten, M. 1994: Direct access to X'-theory: evidence from Korean and Turkish adults learning German. In Hoekstra, T. and Schwartz, B.D., editors, Language acquisition studies in generative grammar. Amsterdam: John Benjamins.

— 1996: Gradual development of L2 phrase structure. Second Language Research 12, 7-39.

Wagner, L. 1999: What children know when they know about viewpoint aspect. In Hollebrandse, B. editer, New Perspectives on Language Acquisition. University of Massachusetts Occasional Papers in Linguistics 22 Amherst, MA: GLSA, 77-86

Wexler, K. 1994: Optional infinitives, head movement, and economy of derivation. In Hornstein, N. and Lightfoot, D., editors, Verb movement. New York: Cambridge University Press, 305-50.

White, L. 2003: Fossilization in steady state L2 grammars: persistent problems with inflectional morphology. Bilingualism: language and cognition 6, 129-41. 
White, L., Valenzuela, E., MacGregor, M., Leung, I. and Ben Ayed, H. 2001: The status of abstract features in interlanguage grammars: gender and number in L2 Spanish". In. Do, A.H.-J., Domínguez, L. and Johansen, A., editors, Proceedings of the 25th Annual Boston University Conference on Language Development. Somerville, MA: Cascadilla Press, 792-802. 